\title{
8p23.1 duplication syndrome differentiated from copy number variation of the defensin cluster at prenatal diagnosis in four new families
}

John CK Barber ${ }^{1,2,3^{*}}$, Dave Bunyann ${ }^{1}$, Merryl Curtis ${ }^{4}$, Denise Robinson ${ }^{4}$, Susanne Morlot ${ }^{5}$, Anette Dermitzel ${ }^{5}$, Thomas Liehrr ${ }^{6}$, Claudia Alves ${ }^{7}$, Joana Trindade ${ }^{7}$, Ana I Paramos ${ }^{8}$, Clare Cooper ${ }^{9}$, Kevin Ocraft ${ }^{9}$, Emma-Jane Taylor ${ }^{1}$, Viv K Maloney ${ }^{1}$

\begin{abstract}
Background: The 8p23.1 duplication syndrome and copy number variation of the 8p23.1 defensin gene cluster are cytogenetically indistinguishable but distinct at the molecular level. To our knowledge, the 8p23.1 duplication syndrome has been described at prenatal diagnosis only once and we report our experience with four further apparent duplications ascertained at prenatal diagnosis.

Methods: Additional material at band 8p23.1 was detected using conventional G-banded cytogenetics in each case. Multiplex Ligation-dependent Probe Amplification (MLPA) or Fluorescence In Situ Hybridisation (FISH) were used depending on whether only DNA (Cases 1 and 4) or cytogenetic preparations (Cases 2 and 3) were available from the laboratory of origin. The extent of the duplication in Case 1 was retrospectively determined using array Comparative Genomic Hybridisation (array CGH).

Results: Three cases of 8p23.1 duplication syndrome were found (Cases 1 to 3). Two were de novo and continued to term and the third, a paternally transmitted duplication, was terminated because of a previous child with psychomotor delay and 8p23.1 duplication syndrome. Case 1 was ascertained with a hypoplastic left heart but the ventricular septal and interventricular defects, in Cases 2 and 3 respectively, were found after ascertainment for advanced maternal age. By contrast, case 4 was a maternally transmitted copy number variation of the defensin cluster with normal outcome.

Conclusions: Our data underline the need to differentiate 8p23.1 duplications from copy number variation of the defensin cluster using FISH, MLPA or array CGH. Cardiac defects were ascertained by ultrasound in only one of the three duplication 8p23.1 pregnancies but were visible in two of the three at 21 to 22 weeks gestation. Our results provide further evidence that both deletion and duplication of the GATA4 transcription factor can give rise to a variety of conotruncal heart defects with variable penetrance and expressivity.
\end{abstract}

\section{Background}

The application of array CGH is rapidly identifying new recurrent microdeletion and microduplication syndromes [1] and a previously unsuspected level of copy number variation which needs to be distinguished from pathogenic change [2]. Among these new syndromes is the $8 \mathrm{p} 23.1$ duplication between the $8 \mathrm{p} 23.1$ olfactory receptor/defensin repeats (ORDRs) at REPD in distal

\footnotetext{
* Correspondence: john.barber@salisbury.nhs.uk

'Wessex Regional Genetics Laboratory, Salisbury NHS Foundation Trust, Salisbury, SP2 8BJ, UK
}

8p23.1 (REPeat Distal) and REPP (REPeat Proximal) in proximal 8p23.1 (Table 1). This genomic disorder is the reciprocal of the $8 \mathrm{p} 23.1$ deletion syndrome [3] and has, to our knowledge, only been confirmed at the molecular level in four families to date [4,5]. Duplications of 8p23.1 have been associated with a variable phenotype that may include one or more of developmental delay, mild dysmorphism and heart defects. The single prenatal case had only mild dysmorphism and normal development at the age of 15 months with no evidence of a heart defect (Case $1[5])$. 
Table 1 MLPA and BAC FISH results in Cases 1 to 4

\begin{tabular}{|c|c|c|c|c|c|c|}
\hline Band & $\mathrm{BAC} / M L P A^{*}$ & $\begin{array}{l}\text { Mb from telomere } \\
\text { (hg } 18 \text { Build } 36 \text { ) }\end{array}$ & $\begin{array}{c}\text { Case } 1 \\
\text { Proband }\end{array}$ & $\begin{array}{c}\text { Case } 2 \\
\text { Proband }\end{array}$ & $\begin{array}{l}\text { Case } 3 \\
\text { Proband, } \\
\text { sister and } \\
\text { father }\end{array}$ & $\begin{array}{c}\text { Case } 4 \\
\text { Proband } \\
\text { and mother }\end{array}$ \\
\hline $8 p 23.3$ & RP11-410N18 & $1,980,652-2,132,993$ & - & Normal & - & - \\
\hline $8 p 23.2$ & RP11-159F11 & $2,215,497-2,435,332$ & - & Normal & - & - \\
\hline $8 p 23.2$ & CSMD1 (4 probes)* & $2,780,282-4,839,736$ & Normal & - & - & Normal \\
\hline $8 p 23.1$ & CTD-2629116 & $6,684,740-6,685,317$ & - & Normal & Normal & - \\
\hline $8 p 23.1$ & ANGPT2* & $6,347,22-6,408,174$ & Normal & - & - & Normal \\
\hline $8 p 23.1$ & DEFB1 (2 probes)* & $6,715,511-6,722,939$ & Normal & - & - & Normal \\
\hline $8 p 23.1$ & DEFA6 (2 probes)* & $6,769,631-6,771,008$ & Normal & - & - & Normal \\
\hline $8 p 23.1$ & DEFA4 (2 probes)* & $6,780,755-6,783,196$ & Normal & - & - & Normal \\
\hline $8 p 23.1$ & DEFA5* & $6,900,239-6,901,669$ & Normal & - & - & Normal \\
\hline REPD & RP11-594D21 & $7,105,087-7,258,467$ & - & Normal & - & - \\
\hline REPD & RP11-122N11 & $7,295,548-7,305,838$ & - & - & dup & - \\
\hline REPD & RP11-1118M6 & $7,286,844-7,462,059$ & - & dup & - & - \\
\hline REPD & RP11-774P7 & $7,318,738-7,396,455$ & - & Normal & _- & - \\
\hline REPD & DEFB4 etc (10 probes)* & $\begin{array}{c}\text { 7,789,609-7,791,647 } \\
\text { Complex }\end{array}$ & Normal & - & - & $\operatorname{trp}$ \\
\hline $8 p 23.1$ & RP11-211C9 & $8,504,285-8,677,721$ & - & dup & dup & - \\
\hline $8 p 23.1$ & MFHASI (MASL1)* & $8,679,409-8,788,541$ & dup & - & - & Normal \\
\hline $8 p 23.1$ & PPP1R3B* & $9,031,186-9,045,630$ & dup & - & - & Normal \\
\hline $8 p 23.1$ & TNKS* & $9,450,855-9,677,266$ & dup & - & - & Normal \\
\hline $8 p 23.1$ & $M S R A^{*}$ & $9,949,189-10,323,803$ & dup & _- & _- & Normal \\
\hline $8 p 23.1$ & $B L K^{*}$ & $11,388,930-11,459,516$ & dup & - & - & Normal \\
\hline $8 p 23.1$ & GATA4* & $11,599,162-11,654,918$ & dup & - & - & Normal \\
\hline $8 p 23.1$ & RP11-589N15 & $11,627,380-11,803,128$ & - & dup & dup & - \\
\hline REPP & RP11-351/21 & $12,233,365-12,434,472$ & - & dup & - & - \\
\hline REPP & RP11-24D9 & $12,433,487-12,590,982$ & - & - & dup & - \\
\hline $8 p 22$ & RP11-433L7 & $14,278,096-14,461,154$ & - & - & Normal & - \\
\hline $8 p 22$ & $M S R 1^{*}$ & $16,009,758-16,094,671$ & Normal & - & - & Normal \\
\hline $8 p 21.3$ & CGAT1* & $19,305,952-19,584,374$ & Normal & - & - & Normal \\
\hline
\end{tabular}

Letters in bold highlight the G-dark bands, REPD and REPP and the results with a change in copy number.

Dashes indicate probes "not tested" and longer dashes (in bold) those "not tested" but expected to show copy number change based on the other results.

BAC names are given without italics and the genes targeted by MLPA probes in italics.

The REPD and REPP repeats mediate a remarkable variety of simple and complex chromosome rearrangements [6] and are themselves copy number variable with 2 to 7 copies of the beta defensin components in the normal population [7]. Numbers as high as 9 to 12 become cytogenetically visible as "euchromatic variants" [7] that are only associated with a predisposition to psoriasis [8]. These high level copy number variations are cytogenetically indistinguishable from the 8p23.1 duplications [4] and both the copy number variants and genuine duplications can be transmitted from parents to children. Here we report on our experience of using follow-up MLPA and FISH testing of apparent cytogenetic duplications of $8 \mathrm{p} 23.1$ detected during prenatal diagnosis. The four cases include two de novo duplications, a paternally transmitted duplication of 8 p23.1 and a benign maternally transmitted defensin copy number variation.

\section{Methods}

Amniotic fluid cells were cultured, G-banded and analysed using established techniques. Quantitative Fluorescent Polymerase Chain Reaction (QF-PCR) analysis was performed using an autosomal multiplex according to a method adapted from Mann et al [9] (Case 1). DNA was extracted using a Qiagen EZ1 machine and MLPA [10] was carried out according to the manufacturer's instructions with the P139 defensin kit which contains 29 probes mapping across the distal short arm of chromosome 8 (Cases 1 and 4) (Table 1) (please see the MRC-Holland 
web site for further information). MLPA PCR products were separated on an ABI 3100 Sequencer, analysed using Applied Biosystems Inc Genotyper version 2.0 (Table 1) and the results collated in an in-house Excel spreadsheet as previously described [11]. Array CGH was carried out with the BlueGnome Cytochip Focus BAC array and BlueFuse software according to the manufacturer's instructions with minor modifications [12] (Case 1). FISH was carried out using standard methods with Ensembl $37 \mathrm{k}$ cloneset bacterial artificial chromosomes (BACs) (Table 1) chosen from the Ensembl web browser http://www.ensembl.org/Homo_sapiens/Location/Genome (Cases 2 and 3). The BACs were grown, validated and prepared for FISH by the National Genetics Reference Laboratory (Wessex). Additional BAC FISH was performed in Case 2 as previously reported [13].

\section{Results \\ Case and family reports}

Case 1 (de novo pathogenic 8p23.1 duplication): A G2P1 lady of 31 was referred for amniocentesis at 21 +2 weeks gestation after a hypoplastic left heart (HLH) has been detected with ultrasound in her unborn daughter. Her previous son (with a different partner) had been phenotypically normal at term and there was no family history of congenital heart defects. She was a non-smoker who had taken no alcohol or drugs during pregnancy. Following genetic counselling at 25 weeks, the parents decided to continue the pregnancy and an infant girl was delivered at 41 weeks gestation with apgar scores of 7 at $1 \mathrm{~min}$ and 9 at $5 \mathrm{~min}$. This girl weighed $3.3 \mathrm{~kg}$ (50th centile), was $53 \mathrm{~cm}$ long (just above 50th centile) and had a head circumference of $38 \mathrm{~cm}$ (97th centile). She underwent successful first stage Norwood surgery for HLH at the age of 2 days. On examination, at just under 3 months of age, she was only $4.26 \mathrm{~kg}$ in weight (0.4th centile) and $55 \mathrm{~cm}$ in length despite tolerating her feeds well. She was being treated with Cephalexin for an E. Coli infection but was otherwise considered well. A transthoracic echocardiogram showed a corrected atrial septum, mild right atrioventricular valvular regurgitation, no neoaortic regurgitation, an RV-PA conduit maximum velocity (V $\max$ ) of $3.7 \mathrm{~m} / \mathrm{sec}$, arch turbulence $\mathrm{V} \max$ of $2.7 \mathrm{~m} / \mathrm{sec}$ and good ventricular function. Blood pressure was $60 / 50$ in the right leg with saturations of $82 \%$ in air. Cardiovascular examination revealed a single second heart sound and normal first heart sounds. There was a $3 / 6$ ejection systolic murmur in the left upper sternal area. The chest was clear and her abdomen soft. Cardiac catheterization was planned. The mother reported no breathlessness in her daughter and had no other concerns.
Case 2 (de novo pathogeneic $8 \mathrm{p} 23.1$ duplication): A lady of 38 was referred for prenatal diagnosis at 18 weeks gestation because of her advanced maternal age. No anomalies were seen with ultrasound at the time but a muscular VSD was detected during an ultrasound scan at 22 weeks. A boy was delivered at 41 weeks and one day of pregnancy with weight $2920 \mathrm{~g}$ (10-25th centile), length $48 \mathrm{~cm}$ (10-25th centile) and OFC $35 \mathrm{~cm}$ (50th centile). Apgar scores were 10/10/10. He was healthy and had no dysmorphic stigmata. Sonographic investigation of the brain was normal. Cardiac echogram showed a muscular VSD, a small bidirectional shunt, PDA, an open foramen ovale, thickened aortic valve and no stenosis. At two months of age a systolic heart murmur was noted.

Case 3 (pathogenic paternally inherited 8p23.1 duplication): A G4P2A1 lady was referred for prenatal diagnosis, during her fourth pregnancy, due to an advanced maternal age of 35 . No ultrasound anomalies were recorded. The mother was a healthy Caucasian who had been through secondary education. Her family history included a mentally retarded brother, who had died at the age of 35 (of unknown causes), and a maternal nephew with learning difficulties who had only attended primary school. Her karyotype was normal.

The mother's first pregnancy had ended in a spontaneous abortion at 20 weeks gestation. No fetal pathology records were available. During her second pregnancy, the mother had been hospitalized at 25 weeks gestation because of the threat of an early delivery. The pregnancy resulted in the eutocic pre-term delivery of a female of $2780 \mathrm{~g}$ with an apgar score of 9 at 1 minute. This girl was hospitalized for two days after birth with a systolic II/IV heart murmur, hyperbilirubinemia, clinical sepsis and a benign congenital cardiopathy consisting of a bicuspid aortic valve and very slight valvular pulmonary stenosis. Global developmental delay was diagnosed when she was 8 years old and she had special educational needs. Her 8p23.1 duplication was identified after the same duplication was found in her mother's fourth pregnancy (see below) and, at 15 years of age, she presented with global developmental delay, psycho-motor delay, speech impairment (dysarthrophonia) and cognitive and socio-emotional difficulties (selective mutism). The mother's 3rd pregnancy ended in a dystocic full term delivery of a healthy girl of $3200 \mathrm{~g}$. This child had normal development and a normal karyotype.

The family was studied after the $8 \mathrm{p} 23.1$ duplication was found in the mother's fourth pregnancy and 8p23.1 duplications were identified in the father and this couple's first liveborn child. The pregnancy was legally terminated at 24 weeks due to the paternally inherited 8 p23.1 duplication identified in the fetus and the psychomotor development delay found in their first child 
with the same duplication. Macroscopic fetal pathology of the male fetus revealed a left hydroureter and hydronephrosis of the kidney, a meso-septal interventricular defect of the heart and cerebral oedema of the brain. Microscopically, nodular hyperplasia of the adrenal cortex, pleural oedema, bilateral dilatation of the alveoli with disruption of the alveolar walls and an emphysema-like presentation were observed. The weight and maturity of the placenta were equivalent to a later gestational age of 29 weeks with evidence of oedema and villitis of unknown etiology.

The father was a Caucasian of 45 years of age with no relevant family history. He had bilateral conductive hearing loss and exostoses which had been surgically removed without clinical improvement. He had only attended primary education and the referring physician described him as "slow". He had the same duplication of 8 p23.1 that had been transmitted to his daughter.

Case 4 (benign maternally inherited defensin copy number variant): A 27 year old lady was referred at 16 +6 weeks gestation for prenatal diagnosis because of an increased risk of Down syndrome estimated, by nuchal translucency determination, at a combined risk of 1 in 235 . The pregnancy continued and a phenotypically normal girl was born at term.
Molecular cytogenetic and molecular genetic results

Case 1

QF-PCR analysis showed no evidence of trisomy 13, 18 or 21 and FISH investigation of cultured cells with the Vysis TUPLE1 (HIRA) probe for 22q11.2 showed a normal hybridisation pattern. However, conventional cytogenetic analysis showed a duplication within the short arm of chromosome 8 at 8 p23.1 (Figure 1A). The abnormality was confirmed in a fetal blood sample. Parental blood karyotypes were normal and the duplication had arisen de novo. MLPA analysis showed that 6 of the 29 probes located between REPD and REPP, including GATA4, were duplicated. Retrospective BAC array CGH analysis revealed increased average intensity ratios for a 3.87- 6.12 $\mathrm{Mb}$ region spanning 6 clones from RP11347L3 to RP11-247B12 (Figure 2A). In accordance with ISCN 2009 [14], the karyotype was: 46, XX, dup(8) (p23.1p23.1)dn.mlpa 8p23.1(P139)x3.arr 8p23.1(RP11347L3-RP11-247B12)x3.

\section{Case 2}

A duplication of 8p23.1 was suspected during conventional chromosome analysis of the amniotic fluid cultures (Figure 1B) and confirmed using FISH with a total of nine BACs. Only BACs mapping to and between REPD and REPP were duplicated (Figure 2B-2E) (Table 1). BAC

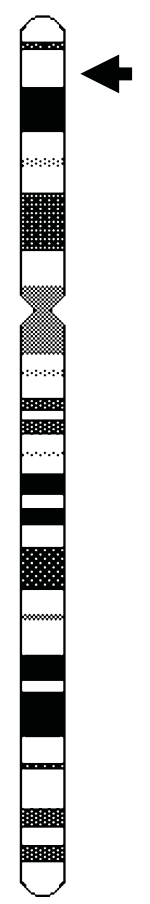

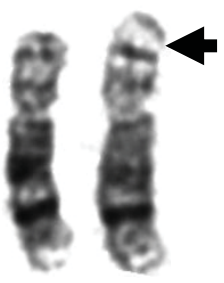

A

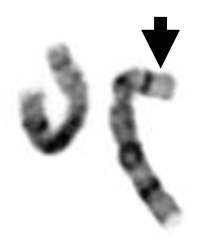

D

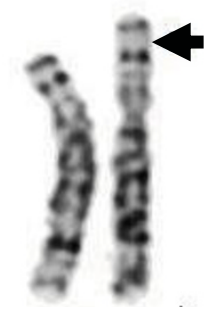

$\mathrm{B}$

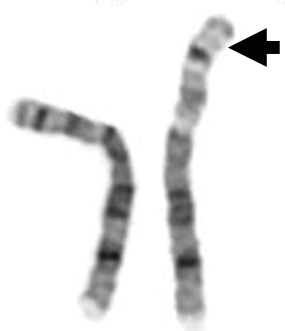

$\mathrm{E}$

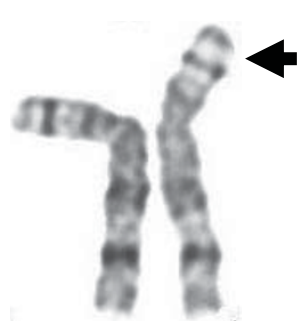

C

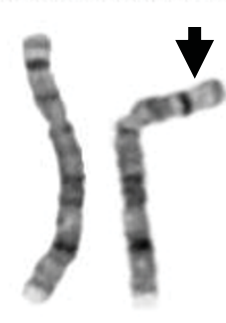

$\mathrm{F}$

Figure 1 G-banded partial karyotypes (A-F). (A) Case 1, (B) Case 2, (C) the Case 3 proband, (D) the father of the proband, (E) the elder sister of the proband and (F) Case 4. The duplicated or variant chromosome is on the right hand side of each chromosome pair and the expanded G-light region of 8p23.1 indicated by the black arrow in each case. Note the similarity of the G-banded copy number variant 8 in Case 4 to the duplicated $8 \mathrm{~s}$ in the probands of Cases 1 to 3 . 


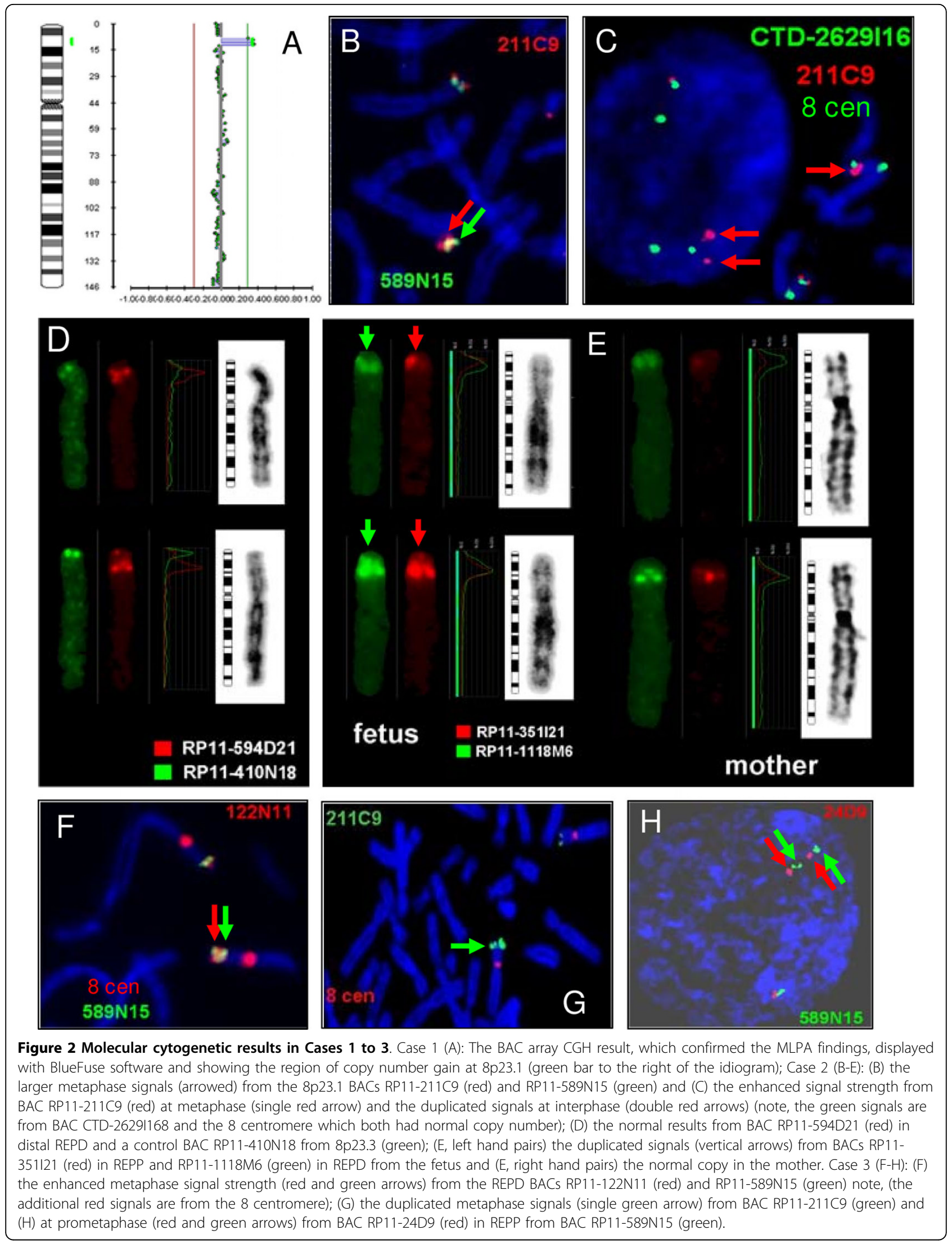


RP11-594D21 from distal REPD gave a normal result (Figure 2D) while REPD BAC RP11-1118M6 was duplicated (Figure 2E) and RP11-774P7 gave a normal result despite being proximal to RP11-1118M6 (data not shown). This may reflect additional structural complexity or uncertainties in the assembly of the human genome in this sequence gap. Normal karyotypes were found in both parents and the duplication was de novo. The karyotype of the fetus was: $46, \mathrm{XY}$, dup $(8)(\mathrm{p} 23.1 \mathrm{p} 23.1) \mathrm{dn}$.ish dup(8)(RP11-410N18+,RP11-159F11+,CTD-2629I16+, RP11-594D21+, RP11-1118M6++, RP11-774P7+,RP11211C9++,RP11-589N15++, RP11-351I21++).

\section{Case 3}

A duplication of $8 \mathrm{p} 23.1$ was suspected during conventional chromosome analysis of the amniotic fluid cultures (Figure 1C) and confirmed using FISH with six BACs. Both the BACs which map to either end of the interval between REPP and REPD were duplicated (Figure $2 \mathrm{~F}-2 \mathrm{H}$ ) as were the BACs which map to the REPP and REPD repeats (Figure $2 \mathrm{~F}$ and $2 \mathrm{H}$ ) (Table 1). Conventional chromosome analysis on the father (Figure 1D) and the family's eldest daughter (Figure 1E) showed the same duplication which was confirmed using FISH on peripheral blood from the father and daughter using the same set of BACs (Table 1). The mother had a normal karyotype and the normal karyotype of her middle daughter was confirmed using FISH. The karyotype of this boy was: $46, \mathrm{XY}, \operatorname{dup}(8)(\mathrm{p} 23.1 \mathrm{p} 23.1)$ pat.ish dup(8) (CTD-2629I16+,RP11-122N11++,RP11-211C9++,RP11589N15++,RP11-24D9++,RP11-433L7+).

\section{Case 4}

A duplication of 8 p23.1 was suspected during conventional chromosome analysis of the amniotic fluid cultures (Figure 1F) and a similar chromosomal pattern was seen in the mother. The normal results at the six genes between REPD and REPP specifically excluded a duplication of 8p23.1 using MLPA with DNA from the fetus and mother. However, there was clear evidence for at least four copies (triplication) of the 8 genes within the copy number variable defensin cluster in both the fetus and mother (data not shown). These include DEFB4, SPAG11, DEFB103A, DEFB104, DEFB105, $D E F B 106, D E F B 107$ and $D E F B 108$. This copy number variation had been transmitted from the phenotypically normal mother and the pregnancy continued. In accordance with ISCN 2009 [14], the karyotype of the fetus was: 46, XX, var(8)(p23.1p23.1).mlpa 8p23.1(P139)x4 mat.

\section{Discussion}

We have presented four prenatal cases in which an 8 p23.1 duplication was suspected on cytogenetic grounds. MLPA or FISH confirmed 8p23.1 duplication syndrome in Cases 1 to 3 and only copy number variation of the defensin cluster in Case 4 . Cases 1 and 2 were de novo, the duplication in Case 3 was directly transmitted from the father and the copy number variation in Case 4 was maternally transmitted. It is reasonable to conclude that Cases 1 to 3 all had a core duplication of $\sim 3.75 \mathrm{Mb}$ between the proximal and distal ORDRs (REPD and REPP) as shown using array $\mathrm{CGH}$ in Case 1 (Figure 2A, Figure 3). When these cases are added to those in the literature, the 8 p23.1 duplication has now been confirmed, using molecular cytogenetic methods, in eleven individuals of whom four cases were de novo and another four had duplications transmitted from a father and two mothers (Table 2). An estimate of the prevalence of this condition can be derived from a recent series of 2,419 diagnostic patients analysed using oligonucleotide array CGH [15]; one dup (8)(p23.1p23.1) was found compared with sixteen 22q11.2 DiGeorge/Velocardiofacial syndrome (DG/ VCFS) deletions. As DG/VCFS has a population frequency of $\sim 1$ in 4,000 [16], the 8p23.1 duplication syndrome has an estimated prevalence of 1 in 64,000 . No examples of the full 8p23.1 duplication syndrome region have been reported among the 29,133 CNVs currently in the Database of Genome Variants (DGV) http://projects.tcag.ca/variation/ (Figure 3).

A summary of the phenotypic data on the eleven patients with $8 \mathrm{p} 23.1$ duplication syndrome is provided in Table 2. Ascertainment has been as a result of congenital heart disease (CHD) in only one of four prenatal cases and one of three postnatal probands but is now the most common single feature having been found in $6 / 11$ individuals. Developmental delay and/or learning difficulties have been found in $5 / 11$ but, of the remaining $6 / 11$, one prenatal case was developmentally normal at 15 months of age and the three prenatal cases reported here have not yet reached an age at which this can assessed. A variable degree of facial dysmorphism was also present in 5/11 individuals. These results are broadly in line with those of Tsai et al [17] but, unfortunately, their results rely on cytogenetics alone and do not differentiate between the duplications and copy number variants. By contrast, partial toe syndactyly has been found in only one mother and son and adrenal anomalies in two probands but not in the mother, of one of these two, who had the same duplication.

Excluding the copy number variable regions, REPP and REPD, the duplicated interval contains 57 genes of which 34 are known and 23 are novel. These include the two transcription factors GATA4 and SOX7 and three micro-RNA loci. Deletions and heterozygous loss of function mutations of the GATA binding protein 4 gene (GATA4, OMIM *600576) are already strongly associated with conotruncal and septal heart defects $[3,18-23]$ and it has been proposed that duplication of 


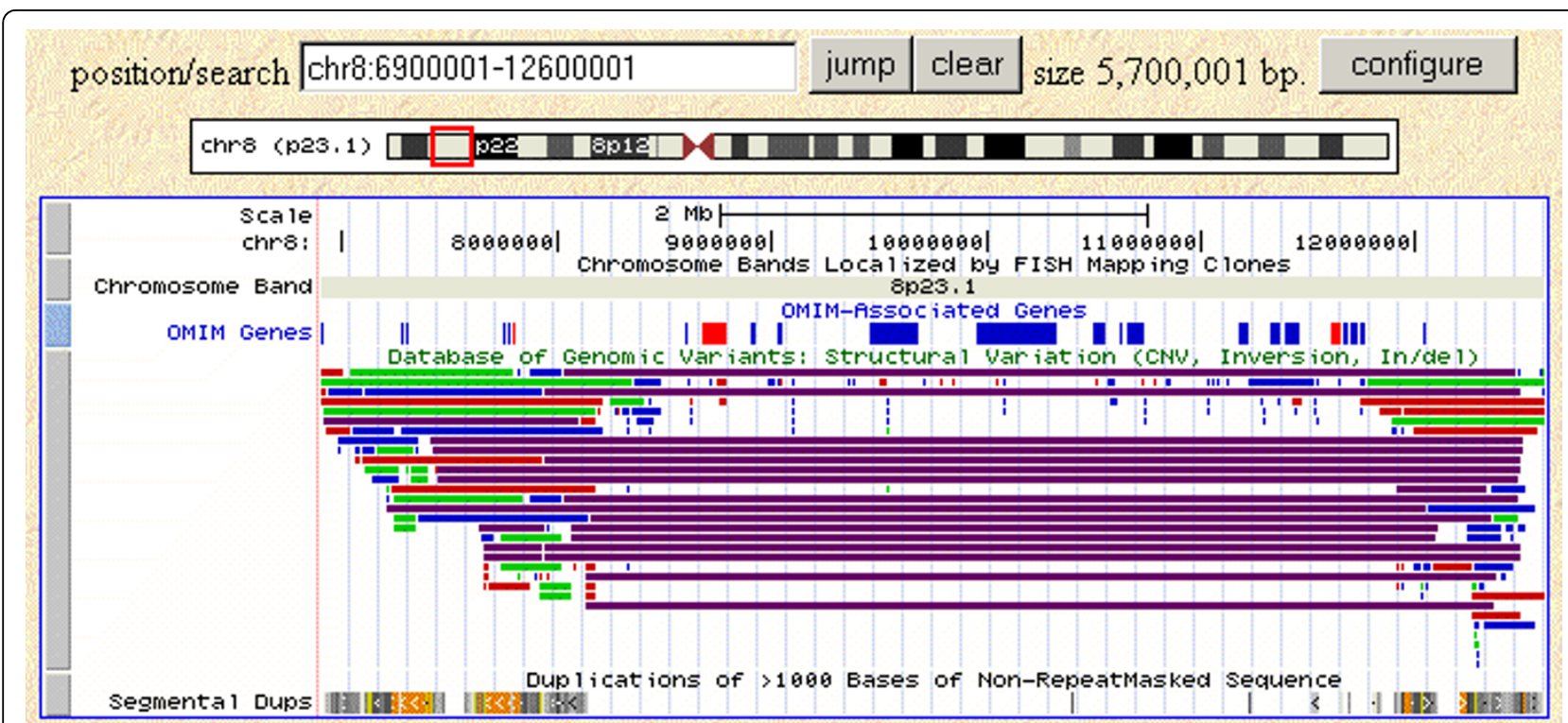

Figure 3 Annotated screenshot of 5.7 Mb of band 8p23.1 (UCSC Genome Browser on Human Mar. 2006 Assembly (hg18)). From bottom to top: the Segmental Duplications that contain the Olfactory Receptor and Defensin Repeats (ORDRs) are labelled REPD and REPP; the $\sim 3.75 \mathrm{Mb}$ core 8p23.1 duplication syndrome interval between REPD and REPP [5] and the $2.5 \mathrm{Mb}$ alternative CHD region proposed by Giglio et al [24] are illustrated by annotated boxes; the multiple copy number variations of REPD and REPP in the Database of Genome Variants (DGV) http://projects.tcag.ca/variation/ is indicated by the red, blue and green lines and the common polymorphic inversion between REPD and REPP by the purple lines; OMIM Morbid genes appear as red boxes and other OMIM genes as blue boxes (or lines); acronyms for the OMIM genes specifically mentioned in the text have been added above in corresponding colours. Note that the DGV does not contain any CNVs that match the 8 p23.1 duplication syndrome region.

GATA4 is responsible for the pulmonary atresia and Tetralogy of Fallot found in two of the four published probands with 8 p23.1 duplication syndrome $[4,5]$. The idea that GATA4 is responsible for the heart defect component of the 8p23.1 duplication syndrome is strengthened by the hypoplastic left heart in Case 1, the complex VSD in Case 2, the meso-septal interventricular heart defect in Case 3, at autopsy, and the mild heart defect in the eldest sister of Case 3.

The existence of a second heart disease gene in a 5-cM region of 8 p23.1 between WI-8327 and D8S1825 $(6,469,539$ to $8,962,119$ base pairs according to UCSC, March 2006) was proposed by Giglio et al [24] (Figure 3). However, the overlap between this $\sim 2.5 \mathrm{Mb}$ region and the REPD to REPP interval contains only four single copy genes (Figure 3), of which neither PRAGMIN, CLDN23 ("OMIM 609203), MFHAS1 (OMIM *605352) nor ERI1 (OMIM *608739) are currently good candidates for heart disease. Thus, it seems more likely that the absence of heart disease in some 8p23.1 duplication syndrome probands [5], four members of a family with a $133 \mathrm{~kb}$ microduplication of the GATA4 gene [25] and seven individuals with a $4.37 \mathrm{Mb}$ duplication of $8 \mathrm{p} 23.1$ to $8 \mathrm{p} 22$ that included GATA4 [26], is more likely to reflect nonpenetrance rather than the existence of a further heart disease gene between REPP and REPD. Normal heart development is thought to require interaction between GATA4 and the T-Box 5 (TBX5) gene $[19,27]$ which suggests that variation in $T B X 5$, or other genes involved in the development of the heart, might modify the consequences of altered GATA4 dosage. We conclude that both duplication and deletion of the GATA4 gene can give rise to a variety of conotruncal and septal heart defects but with variable penetrance and expressivity.

Other candidate genes derived from atypical microdeletions of proximal 8p23.1 may be considered candidate genes for features of the 8p23.1 duplication syndrome $[3,28]$ (Figure 3). These include the TRF1-interacting, ankyrin related ADP-ribose polymerase gene (TNKS,

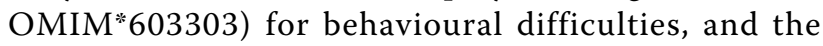
SRY-Box 7 transcription factor (SOX7, OMIM *612202) for the developmental delay, as mutations of the related SOX3 gene have been associated with X-linked mental retardation [28]. By contrast, the diaphragmatic hernia found in a number of patients with the reciprocal deletion syndrome [29-31] has not, to our knowledge, been recorded in any 8 p23.1 duplication syndrome patient to date.

There was evidence, using FISH, for both REPD and REPP being included in the duplication in Case 2 (Figure $2 \mathrm{E}$ ) and Case 3 (Figure $2 \mathrm{~F}$ and $2 \mathrm{H}$ ) but not for the inclusion of either repeat in Case 1 using MLPA. REPP 
Table 2 Features of the present and previous cases of the 8p23.1 duplication syndrome

\begin{tabular}{|c|c|c|c|c|c|c|c|c|c|c|c|}
\hline $\begin{array}{l}\text { Physical } \\
\text { findings } \\
\text { at birth or } \\
\text { diagnosis }\end{array}$ & $\begin{array}{c}\text { Present } \\
\text { Case } 1\end{array}$ & $\begin{array}{l}\text { Present } \\
\text { Case } 2\end{array}$ & $\begin{array}{l}\text { Present } \\
\text { Case } 3 \\
\text { Proband }\end{array}$ & $\begin{array}{c}\text { Present } \\
\text { Case } 3 \\
\text { Sister }\end{array}$ & $\begin{array}{l}\text { Present } \\
\text { Case } 3 \\
\text { Father }\end{array}$ & $\begin{array}{l}\text { Barber } \\
\text { et al. } \\
(2008) \\
\text { Case } 1\end{array}$ & $\begin{array}{l}\text { Barber } \\
\text { et al. } \\
(2005) \\
\text { Case } 1\end{array}$ & $\begin{array}{l}\text { Barber } \\
\text { et al. } \\
(2008) \\
\text { Family } 1 \\
\text { Proband }\end{array}$ & $\begin{array}{l}\text { Barber } \\
\text { et al. } \\
(2008) \\
\text { Family } 1 \\
\text { Mother }\end{array}$ & $\begin{array}{l}\text { Barber } \\
\text { et al. } \\
\text { (2008) } \\
\text { Family } 2 \\
\text { Proband }\end{array}$ & $\begin{array}{c}\text { Barber } \\
\text { et al. } \\
(2008) \\
\text { Family } \\
2 \\
\text { Mother }\end{array}$ \\
\hline $\begin{array}{l}\text { Ascertainment } \\
\text { of dup(8) }\end{array}$ & $\mathrm{CHD}$ & AMA & AMA & AMA & AMA & $\begin{array}{l}\text { 1:150 } \\
\text { risk }\end{array}$ & $\begin{array}{l}\mathrm{DD} ; \\
\mathrm{CHD}\end{array}$ & PNAI & Daughter & DYS & Son \\
\hline $\begin{array}{l}\text { Prenatal/ } \\
\text { Postnatal }\end{array}$ & Pre & Pre & Pre & Pre & Pre & Pre & Post & Post & Post & Post & Post \\
\hline $\begin{array}{l}\text { Pregnancy } \\
\text { continued }\end{array}$ & $Y$ & $Y$ & $\mathrm{~N}$ & $\mathrm{n} / \mathrm{a}$ & $\mathrm{n} / \mathrm{a}$ & $Y$ & $\mathrm{n} / \mathrm{a}$ & $\mathrm{n} / \mathrm{a}$ & $\mathrm{n} / \mathrm{a}$ & $\mathrm{n} / \mathrm{a}$ & $\mathrm{n} / \mathrm{a}$ \\
\hline Sex & $\mathrm{F}$ & M & $M$ & $\mathrm{~F}$ & M & $\mathrm{F}$ & $\mathrm{F}$ & $\mathrm{F}$ & $\mathrm{F}$ & $M$ & $\mathrm{~F}$ \\
\hline $\begin{array}{l}\text { Delivery } \\
\text { gestation (wks) }\end{array}$ & 41 & $41+1$ & 22 & $<40$ & $n / a$ & 40 & $n / k$ & 42 & $n / a$ & $40+5$ & $\mathrm{n} / \mathrm{a}$ \\
\hline $\begin{array}{l}\text { Apgar } \\
\text { scores }\end{array}$ & $7 ; 9$ & $10 ; 10 ; 10$ & $n / a$ & 9 & $n / a$ & $8 ; 9$ & $n / a$ & $n / a$ & $n / a$ & $n / a$ & $n / a$ \\
\hline $\begin{array}{l}\text { Birth } \\
\text { weight (kg) }\end{array}$ & 3.3 & 2.92 & $n / r$ & 2.78 & $n / k$ & 3.15 & $n / k$ & 3.6 & $?$ & 3.39 & $?$ \\
\hline $\mathrm{OFC}(\mathrm{cm})$ & 38 & 35 & $n / r$ & $?$ & $n / k$ & 33.6 & $n / k$ & $n / r$ & $n / k$ & 39.5 & $?$ \\
\hline $\begin{array}{l}\text { Age at } \\
\text { examination }\end{array}$ & $3 / 12$ & Neonate & $22 / 52$ & 15 & 45 & $15 / 12$ & 8 & 4 & $n / r$ & $22 / 12$ & $n / r$ \\
\hline $\begin{array}{l}\text { Developmental } \\
\text { delay }\end{array}$ & $\mathrm{n} / \mathrm{a}$ & $n / a$ & $\mathrm{n} / \mathrm{a}$ & ++ & $?$ & $n$ & + & - & - & - & + \\
\hline $\begin{array}{l}\text { Learning } \\
\text { difficulties }\end{array}$ & $n / a$ & $\mathrm{n} / \mathrm{a}$ & $n / a$ & + & + & $n / a$ & + & - & + & - & + \\
\hline $\begin{array}{l}\text { Facial } \\
\text { dysmorphism }\end{array}$ & - & - & - & - & - & + & + & $+/-$ & + & ++ & ++ \\
\hline $\begin{array}{l}\text { Congenital } \\
\text { heart defects }\end{array}$ & ++ & ++ & + & ++ & - & $n$ & + & + & - & - & - \\
\hline $\begin{array}{l}\text { Neurological } \\
\text { defects }\end{array}$ & - & $n$ & $?+$ & + & - & $n$ & - & + & - & - & - \\
\hline Syndactyly & - & - & - & - & - & - & - & - & - & + & + \\
\hline $\begin{array}{l}\text { Adrenal } \\
\text { anomalies }\end{array}$ & - & - & + & - & - & - & - & ++ & - & - & - \\
\hline $\begin{array}{l}\text { Hydronephrosis } \\
\text { and } \\
\text { hydroureter }\end{array}$ & - & - & + & - & - & - & - & - & - & - & - \\
\hline $\begin{array}{l}\text { Alveolar } \\
\text { anomalies }\end{array}$ & - & - & + & - & - & - & - & - & - & - & - \\
\hline Hearing & - & - & - & - & + & - & - & - & - & - & - \\
\hline
\end{tabular}

Exostoses

AMA: Advanced Maternal Age; CHD: Congenital heart defect; DD: Developmental delay;

DYS: Facial dysmorphism; n: no evidence; n/a: not applicable; n/k: not known; n/r: not recorded; PNAl: Primary Neonatal Adrenal Insufficiency; $Y=$ Yes; $+=$ present $;-=$ absent.

was also implicated in a previously published case (Family 1 [5]). Altered copy number might be expected at either or both repeats if the reciprocal deletions and duplications are generated by ectopic recombination (or NAHR) between the repeats [6]. Alternatively, altered copy number may be due to independent copy number variation of the ORDRs themselves.

Benign copy number variation of the defensin cluster was found in over $14 \%$ of a recent series of 1,275 patients analysed using array CGH [32], but cytogenetically visible amplifications, of the kind found in Case 4, are uncommon. These segregate in families with no significant clinical or reproductive effects other than a predisposition to Crohn's disease at low copy number [33] and psoriasis at high copy number [8]. Most chromosomes 8 have two copies of the defensin cluster and most individuals a total of four [34]. Thus, the triplication of the defensin cluster, relative to control DNA, 
implies a total of 12 copies in the Case 4 fetus and her mother. If the normal chromosome 8 had 2 copies, the variant chromosome would have 10 copies of the ORDR repeat and, as the repeat is a minimum of $240 \mathrm{~kb}$ in size [7], the ORDR array would extend to at least $2.4 \mathrm{Mb}$ and thus become cytogenetically visible in the light microscope (Figure 1F) [4,7].

Both FISH and MLPA have been reliably used to confirm or exclude an 8p23.1 duplication between REPD and REPP. However, even normal chromosomes 8 can look duplicated with BACs that map to these repeats and thus differential signal strength between FISH probes does not constitute proof that copy number variation of REPD or REPP is the cause of an increase in the size of the $8 \mathrm{p} 23.1$ band. Recent evidence also suggests that the defensin clusters are switched between REPD to REPP by the polymorphic inversion between them [35], and this may be expected to change the appearance of the FISH signals seen on homologous pairs of chromosome 8 even if their copy number is the same or similar. Array CGH will also discriminate the duplication from the variant, and exclude additional imbalances, but careful choice of control samples may be required to accurately confirm the extent of the defensin copy number variation in all cases.

\section{Conclusions}

In conclusion, our results underline the need to distinguish the 8p23.1 duplication from benign defensin copy number variation at prenatal diagnosis. Direct transmission of duplications and copy number variants from a parent to a child has been found on multiple occasions and transmission does not therefore discriminate between copy number variations of the defensin cluster and the 8p23.1 duplication syndrome. Cardiac defects were ascertained by ultrasound in only one of the three duplication 8p23.1 pregnancies but were visible in two of the three at 21 to 22 weeks gestation. Phenotypic data also indicate a relatively mild but variable syndrome and support the idea that duplication of the GATA4 transcription factor can give rise to a variety of conotruncal or septal heart defects with variable penetrance and expressivity.

\section{List of abbreviations}

AMA: Advanced maternal age; BAC: Bacterial Artificial Chromosome; array CGH: array Comparative Genomic Hybridisation; CHD: Congenital heart disease; DGV: Database of Genome Variants; DNA: De-oxyo Ribose Nucleic Acid; FISH: Fluorescence In Situ Hybridisation HLH: Hypoplastic Left Heart; MCA: Multiple Congenital Anomalies; Multiple Ligation-dependent Probe Amplification (MLPA); OFC: Occipito-Frontal Circumference; PDA: Patent Ductus Arteriosus; ORDR:
Olfactory Receptor and Defensin Repeat; Patent Ductus Arteriosus; PNAI: Primary Neonatal Adrenal Insufficiency; QF-PCR: Quantitative Fluorescent Polymerase Chain Reaction; REPD: REPeat Distal; REPP: REPeat Proximal; VSD: Ventricular Septal Defect.

\section{Acknowledgements}

We should like to thank all the family members concerned. We should also like to acknowledge Sian Morgan, Sally Spillane and Sian Jose, for their cytogenetic and molecular cytogenetic expertise, as well as Dr Prasad Manne and Dr Christine Conner for cardiological and obstetric details of Case 1 (Cardiff, UK). We also thank Professor Dr Sergio Castedo (GDPN, Porto) for additional information on Case 3 as well as Harveer Jhalli for cytogenetic analysis and Mr Magd for clinical information on Case 4.

\section{Author details}

${ }^{1}$ Wessex Regional Genetics Laboratory, Salisbury NHS Foundation Trust, Salisbury, SP2 8BJ, UK. ${ }^{2}$ National Genetics Reference Laboratory (Wessex), Salisbury NHS Foundation Trust, Salisbury, SP2 8BJ, UK. ${ }^{3}$ Human Genetics Division, Southampton University School of Medicine, Southampton, SO16 6YD, UK. ${ }^{4}$ Institute of Medical Genetics, University Hospital Wales, Cardiff, CF14 4XW, UK. ${ }^{5}$ Medizinisches Versorgungszentrum wagnerstibbe, Georgstr 50, Hannover, Germany. ${ }^{6}$ Institut für Humangenetik und Anthropologie, Jena University Hospital, Jena, Germany. ${ }^{7}$ GDPN, Genetica Medica e Diagnostico Pre-natal, Porto, Portugal. ${ }^{8}$ Prenatal Diagnosis Unit, District Hospital, Faro, Portugal. ${ }^{9}$ Centre for Medical Genetics, Nottingham City Hospital, Nottingham, NG5 1PB, UK.

\section{Authors' contributions}

JCKB assembled the results and drafted the manuscript; DB carried out the MLPA analyses on Cases 1 and 4; MC and DR provided the laboratory and clinical information on Case 1; SM and AD provided the laboratory and clinical information on Case 2 and TL contributed the additional FISH results; CA, JT and AIP provided the laboratory and clinical information on Case 3 and her family; $\mathrm{CC}$ and $\mathrm{KO}$ provided the laboratory and clinical information on Case 4; EJT drafted Table 2; VKM prepared and validated the FISH probes and carried out the FISH analyses on Cases 2 and 3. All authors read and approved the final manuscript.

\section{Competing interests}

The authors declare that they have no competing interests.

Received: 14 October 2009 Accepted: 18 February 2010 Published: 18 February 2010

\section{References}

1. Slavotinek AM: Novel microdeletion syndromes detected by chromosome microarrays. Hum Genet 2008, 124:1-17.

2. Sharp AJ: Emerging themes and new challenges in defining the role of structural variation in human disease. Hum Mutat 2009, 30:135-144.

3. Devriendt K, Matthijs G, Van Dael R, et al: Delineation of the critical deletion region for congenital heart defects, on chromosome 8p23.1. Am J Hum Genet 1999, 64:1119-1126.

4. Barber JCK, Maloney V, Hollox EJ, Stuke-Sontheimer A, du Bois G, Daumiller E, Klein-Vogler U, Dufke A, Armour JAL, Liehr T: Duplications and copy number variants of 8 p23.1 are cytogenetically indistinguishable but distinct at the molecular level. Eur J Hum Genet 2005, 13:1131-1136.

5. Barber JCK, Maloney VK, Huang S, Bunyan DJ, Cresswell L, Kinning E, Benson A, Cheetham T, Wyllie J, Lynch SA, Zwolinski S, Prescott L, Crow Y, Morgan R, Hobson E: 8p23.1 duplication syndrome; a novel genomic condition with unexpected complexity revealed by array CGH. Eur J Hum Genet 2008, 16:18-27.

6. Hollox EJ, Barber JC, Brookes AJ, Armour JA: Defensins and the dynamic genome: what we can learn from structural variation at human chromosome band 8p23.1. Genome Res 2008, 18:1686-1897.

7. Hollox EJ, Armour JAL, Barber JCK: Extensive normal copy number variation of a $\beta$-defensin antimicrobial gene cluster. Am J Hum Genet 2003, 73:591-600. 
8. Hollox EJ, Huffmeier U, Zeeuwen PL, Palla R, Lascorz J, Rodijk-Olthuis D, Kerkhof van de PC, Traupe H, de Jongh G, den Heijer M, Reis A, Armour JA, Schalkwijk J: Psoriasis is associated with increased beta-defensin genomic copy number. Nat Genet 2008, 40:23-25.

9. Mann K, Donaghue C, Fox SP, Docherty Z, Ogilvie CM: Strategies for the rapid diagnosis of chromosome aneuploidy. Eur J Hum Genet 2004, 12:907-915.

10. Schouten JP, McElgunn CJ, Waaijer R, Zwijnenburg D, Diepvens F, Pals G: Relative quantification of 40 nucleic acid sequences by multiplex ligation-dependent probe amplification. Nucl Acid Res 2002, 30:e57.

11. Bunyan DJ, Eccles DM, Sillibourne J, Wilkins E, Thomas NS, Shea-Simonds J, Duncan PJ, Curtis CE, Robinson DO, Harvey JF, Cross NCP: Dosage analysis of cancer predisposition genes by multiplex ligation-dependent probe amplification. Br J Cancer 2004, 91:1155-1159.

12. Mantripragada KK, Thuresson AC, Piotrowski A, Díaz de Ståhl T, Menzel U, Grigelionis G, Ferner RE, Griffiths S, Bolund L, Mautner V, Nordling M, Legius E, Vetrie D, Dahl N, Messiaen L, Upadhyaya M, Bruder CE, Dumanski JP: Identification of novel deletion breakpoints bordered by segmental duplications in the NF1 locus using high resolution arrayCGH. J Med Genet 2006, 43:28-38.

13. Weise A, Starke $H$, Heller A, Tönnies H, Volleth M, Stumm M, Gabriele S, Nietzel A, Claussen U, Liehr T: Chromosome 2 aberrations in clinical cases characterised by high resolution multicolour banding and region specific FISH probes. J Med Genet 2002, 39:434-439.

14. Shaffer LG, Slovak ML, Campbell LJ, (eds): ISCN 2009: An International System for Human Cytogenetic Nomenclature. Karger S, Basel 2009.

15. Rudd MK, Keene J, Bunke B, Kaminsky EB, Adam MP, Mulle JG, Ledbetter DH, Martin CL: Segmental duplications mediate novel, clinically relevant rearrangements. Hum Molec Genet 2009, 18:2957-62.

16. Devriendt K, Fryns JP, Mortier G, van Thienen MN, Keymolen K: The annual incidence of DiGeorge/velocardiofacial syndrome. J Med Genet 1998, 35:789-790.

17. Tsai CH, Graw SL, McGavran L: 8p23 duplication reconsidered: is it a true euchromatic variant with no clinical manifestation? J Med Genet 2002, 39:769-74

18. Pehlivan $T$, Pober BR, Brueckner M, Garrett $S$, Slaugh $R$, Van Rheeden $R$, Wilson DB, Watson MS, Hing AV: GATA4 haploinsufficiency in patients with interstitial deletion of chromosome region 8p23.1 and congenital heart disease. Am J Med Genet 1999, 83:201-206.

19. Garg V, Kathiriya IS, Barnes R, Schluterman MK, King IN, Butler CA, Rothrock CR, Eapen RS, Hirayama-Yamada K, Joo K, Matsuoka R, Cohen JC, Srivastava D: GATA4 mutations cause human congenital heart defects and reveal an interaction with TBX5. Nature 2003, 424:443-447.

20. Okubo A, Miyoshi O, Baba K, Takagi M, Tsukamoto K, Kinoshita A, Yoshiura K, Kishino T, Ohta T, Niikawa N, Matsumoto N: A novel GATA4 mutation completely segregated with atrial septal defect in a large Japanese family. J Med Genet 2004, 41:e97.

21. Hirayama-Yamada K, Kamisago M, Akimoto K, Aotsuka H, Nakamura Y, Tomita H, Furutani M, Imamura S, Takao A, Nakazawa M, Matsuoka R: Phenotypes with GATA4 or NKX2.5 mutations in familial atrial septal defect. Am J Med Genet Part A 2005, 135:47-52.

22. Reamon-Buettner SM, Borlak J: GATA4 zinc finger mutations as a molecular rationale for septation defects of the human heart. $J$ Med Genet 2005, 42:e32.

23. Tomita-Mitchell A, Maslen CL, Morris CD, Garg V, Goldmuntz E: GATA4 sequence variants in patients with congenital heart defects. J Med Genet 2007, 44:779-783.

24. Giglio S, Graw SL, Gimelli G, Pirola B, Varone P, Voullaire L, Lerzo F, Rossi E, Dellavecchia C, Bonaglia MC, Digilio MC, Giannotti A, Marino B, Carrozzo R, Korenberg JR, Danesino C, Sujansky E, Dallapiccola B, Zuffardi O: Deletion of a 5-cM region at chromosome 8 p23 is associated with a spectrum of congenital heart defects. Circulation 2000, 102:432-437.

25. Joziasse IC, Smagt van der JJ, Poot M, Hochstenbach R, Nelen MR, van Gijn M, Dooijes D, Mulder BJ, Doevendans PA: A duplication including GATA4 does not co-segregate with congenital heart defects. Am J Med Genet Part A 2009, 149A:1062-1066.

26. Zogopoulos G, Ha KC, Naqib F, Moore S, Kim H, Montpetit A, Robidoux F, Laflamme P, Cotterchio M, Greenwood C, Scherer SW, Zanke B, Hudson TJ, Bader GD, Gallinger S: Germ-line DNA copy number variation frequencies in a large North American population. Hum Genet 2007, 122:345-53.
27. Maitra M, Schluterman MK, Nichols HA, Richardson JA, Lo CW, Srivastava D, Garg V: Interaction of Gata4 and Gata6 with Tbx5 is critical for normal cardiac development. Dev Biol 2009, 326:368-377.

28. Páez MT, Yamamoto T, Hayashi K, Yasuda T, Harada N, Matsumoto N, Kurosawa K, Furutani Y, Asakawa S, Shimizu N, Matsuoka R: Two patients with atypical interstitial deletions of 8p23.1: mapping of phenotypical traits. Am J Med Genet Part A 2008, 146A:1158-1165.

29. Shimokawa O, Miyake N, Yoshimura T, Sosonkina N, Harada N, Mizuguchi T, Kondoh S, Kishino T, Ohta T, Remco V, Takashima T, Kinoshita A, Yoshiura K, Niikawa N, Matsumoto N: Molecular characterization of del(8)(p23.1p23.1) in a case of congenital diaphragmatic hernia. Am J Med Genet Part A 2005, 136:49-51.

30. Slavotinek A, Lee SS, Davis R, Shrit A, Leppig KA, Rhim J, Jasnosz K, Albertson D, Pinkel D: Fryns syndrome phenotype caused by chromosome microdeletions at 15q26.2 and 8p23.1. J Med Genet 2005, 42:730-736.

31. Baynam G, Goldblatt J, Walpole I: Deletion of 8p23.1 with features of Cornelia de Lange syndrome and congenital diaphragmatic hernia and a review of deletions of 8 p23.1 to 8pter. ?A further locus for Cornelia de Lange syndrome. Am J Med Genet Part A 2008, 146A:1565-1570.

32. Whitby $H$, Tsalenko A, Aston E, Tsang P, Mitchell S, Bayrak-Toydemir P, Hopkins C, Peters G, Bailey DK, Bruhn L, Brothman AR: Benign copy number changes in clinical cytogenetic diagnostics by array $\mathrm{CGH}$. Cytogenet Genome Res 2008, 123:94-101.

33. Fellermann $\mathrm{K}$, Stange DE, Schaeffeler E, Schmalzl H, Wehkamp J, Bevins CL, Reinisch W, Teml A, Schwab M, Lichter P, Radlwimmer B, Stange EF: A chromosome 8 gene-cluster polymorphism with low human betadefensin 2 gene copy number predisposes to Crohn disease of the colon. Am J Hum Genet 2006, 79:439-448.

34. Hollox EJ: Copy number variation of beta-defensins and relevance to disease. Cytogenet Genome Res 2008, 123:148-155.

35. Abu Bakar S, Hollox EJ, Armour JA: Allelic recombination between distinct genomic locations generates copy number diversity in human betadefensins. Proc Natl Acad Sci USA 2009, 106:853-858.

doi:10.1186/1755-8166-3-3

Cite this article as: Barber et al:: 8p23.1 duplication syndrome

differentiated from copy number variation of the defensin cluster at prenatal diagnosis in four new families. Molecular Cytogenetics 2010 3:3.

\section{Submit your next manuscript to BioMed Central and take full advantage of:}

- Convenient online submission

- Thorough peer review

- No space constraints or color figure charges

- Immediate publication on acceptance

- Inclusion in PubMed, CAS, Scopus and Google Scholar

- Research which is freely available for redistribution 